\title{
Article
}

\section{Tablet Use Affects Preschoolers' Executive Function: fNIRS Evidence from the Dimensional Change Card Sort Task}

\author{
Hui Li ${ }^{1, *(\mathbb{D})}$, Dandan $\mathrm{Wu}^{1}{ }^{1}$, Jinfeng Yang ${ }^{2}$, Jiutong Luo ${ }^{3}$, Sha Xie ${ }^{4}$ and Chunqi Chang ${ }^{2, *}$ \\ 1 School of Education, Macquarie University, Sydney, NSW 2109, Australia; dandan.wu4@students.mq.edu.au \\ 2 School of Biomedical Engineering, Health Science Center, Shenzhen University, Shenzhen 518061, China; \\ yangjinfeng2017@email.szu.edu.cn \\ 3 Center for Educational Science and Technology, Beijing Normal University at Zhuhai, Zhuhai 519085, China; \\ jtluo@bnu.edu.cn \\ 4 Normal College, The GBA Institute of Educational Research, and The Institute of KEEP \\ Collaborative Innovation, Shenzhen University, Shenzhen 518061, China; xiesha@szu.edu.cn \\ * Correspondence: philip.li@mq.edu.au (H.L.); cqchang@szu.edu.cn (C.C.)
}

check for

updates

Citation: Li, H.; Wu, D.; Yang, J.; Luo, J.; Xie, S.; Chang, C. Tablet Use Affects Preschoolers' Executive Function: fNIRS Evidence from the Dimensional Change Card Sort Task. Brain Sci. 2021, 11, 567. https://doi.org/ 10.3390/brainsci11050567

Academic Editor: Kurtulus Izzetoglu

Received: 25 March 2021

Accepted: 27 April 2021

Published: 29 April 2021

Publisher's Note: MDPI stays neutral with regard to jurisdictional claims in published maps and institutional affiliations.

Copyright: (c) 2021 by the authors. Licensee MDPI, Basel, Switzerland. This article is an open access article distributed under the terms and conditions of the Creative Commons Attribution (CC BY) license (https:// creativecommons.org/licenses/by/ $4.0 /)$.

\begin{abstract}
This study aims to examine the impact of heavy use of tablets on preschoolers' executive function during the Dimensional Change Card Sort (DCCS) task using the functional near-infrared spectroscopy (fNIRS). Altogether, 38 Chinese preschoolers $\left(M_{\text {age }}=5.0\right.$ years, $S D=0.69$ years, 17 girls) completed the tasks before the COVID-19 lockdown. Eight children never used tablets, while 16 children were diagnosed as the 'heavy-user'. The results indicated that: (1) the 'non-user' outperformed the 'heavy-user' with a significantly higher correct rate in the DCCS task; (2) the two groups differed significantly in the activation of the prefrontal cortex (BA 9): the 'non-user' pattern is normal and healthy, whereas the 'heavy-user' pattern is not normal and needs further exploration.
\end{abstract}

Keywords: pad use; executive function; fNIRS evidence; Dimensional Change Card Sort (DCCS) task; preschoolers

\section{Introduction}

Rapidly advancing information and communication technologies (ICT) have nurtured a brand-new generation of 'digital children' in this 'digital age'. Infants and young children are exposed to more technologies than before as they have more devices and apps readily available for their use, resulting in increased screen time and tablet use [1]. This phenomenon has worried public health organizations, parents, and scholars who are seriously concerned about the benefits and damages of tablet use in the early years (ages 0-5) [2]. So far, many studies have examined the impact of tablet use on young children's brain development, but the results are still mixed [3]. These inconclusive results have created difficulties in making policies for early ICT use and education and have caused heated debates between the advocates and dissenters of the 'digital child' and tablet use [4]. Therefore, there is an urgent need for rigorous neuroimaging evidence to settle the debate. To fill this research gap, this article explored the impact of heavy use of tablets on young children's executive function in the prefrontal cortex using functional near-infrared spectroscopy (fNIRS).

\subsection{Tablet Use and Early Childhood Development}

Touchscreen tablet computers, hereafter referred to as 'tablets', are lightweight, mobile devices with a flat, panel screen used for both display and input $[5,6]$. Tablets feature multimedia playback, digital photography, multitouch interface, long battery life, instant start-up, and wireless Internet connectivity, thus have been easily and frequently used by young children as tools for entertainment and education [7]. A recent study found that tablets were especially popular for viewing videos, learning, and gaming in young children, 
and the number of users increased with age [8]. For instance, according to Lawrence [9], about $80 \%$ of top-selling paid educational apps in Apple's App Store were marketed for young children's consumption in 2017. Recently, the COVID-19 lockdown in 2020 has caused a sudden increase in tablet use among preschoolers, who had to do online learning at home [7].

Tablet use in the early years might have posited both benefits and risks in early childhood development, thus deserves empirical studies. Rocha and Nunes reviewed 11 studies and found that the damages were superior to the benefits, especially when screen time increased [2]. They also underscored the difficulties in finding studies directed to the desired age and type of electronic device, which is a potential cause of bias. Small et al. conducted another systematic review and reported harmful effects such as heightened attention-deficit symptoms, impaired emotional and social intelligence, technology addiction, social isolation, impaired brain development, and disrupted sleep [3]. Meanwhile, they also found that various apps, videogames, and other online tools might benefit brain health in adulthood. However, no neuroimaging studies have explored tablet use's impact on young children's executive function, as indicated by the following review.

\subsection{Neuroimaging Studies on Early Executive Function}

Executive function (EF) refers to the brain's specific cognitive, transactional, selfregulating functions that can control and direct one's attention amid distractions, regulate emotional reactivity, inhibit behavior from responding to environmental demands and fulfill goals [10,11]. Miyake et al. identified three core components of EF: inhibition, working memory, and cognitive shifting [12]. The Dimensional Card Change Sort (DCCS) task requires inhibition, working memory, and cognitive shifting to complete the card sorting, thus providing insights into the wide spectrum of EF processes and the associated neural changes in early childhood [13].

However, young children might have difficulties in taking functional magnetic resonance imaging (fMRI) because they cannot stay still in the tube for a long time. Therefore, very few neuroimaging studies had explored preschoolers' EF during the DCCS task until Moriguchi and Hiraki conducted the fNIRS study for the first time. This success has inspired more fNIRS studies to examine EF using the DCCS task [14]. The results jointly indicated that the prefrontal area was substantially involved in the cognitive shifting [15]. Recently, Xie et al. found that the children in the DCCS pass group (with cognitive shifting) significantly activated the prefrontal cortex than those in the perseverate group who did not complete the cognitive shifting, and the activation in the prefrontal region was significantly correlated with children's executive function [10]. Very recently, Li et al. proposed and confirmed the 'V-shape curve' theory by identifying a significant decrease-increase cycle in BA 9, the neural correlate of cognitive shifting [11]. In conclusion, the existing fNIRS studies have jointly confirmed the prefrontal cortex (e.g., BA 9), which is also the region of interest in this study, was the neural correlate of cognitive shifting during the DCCS tasks.

EF develops rapidly during the preschool years and is sensitive to environmental influences and learning experiences [16]. Since the early 2010s, tablet use has become increasingly prevalent in young children's daily life and has prompted substantial public concerns about its impact on children's brain development $[17,18]$. Most of the existing studies have reported survey and behavioral evidence [2,3], yet no neuroimaging evidence has been reported. This study was thus dedicated to filling this research gap by conducting the DCCS task with fNIRS to understand the impact of heavy use of tablets on EF. Accordingly, the following research questions guided this study.

1. Will the heavy users perform significantly differently from the non-users in the DCCS task?

2. What are the significant differences in prefrontal activation as evidenced by fNIRS between the heavy-users and non-users in the DCCS task? 


\section{Materials and Methods}

\subsection{Participants}

Originally, 64 right-handed Chinese preschoolers and their parents consented to participate in this study. All the parents of participating children provided written consent and were informed verbally of the study's purpose and the fNIRS experiments' safety. The University Ethics Committee approved the experiments. Because of the unexpected COVID-19 lockdown, only 42 of them completed this study. Four failed to complete the experiments, thus were excluded from this study, resulting in a final sample of 38 children (ages 4 to 6.3 years, $M_{\text {age }}=5.0$ years, $S D=0.69$ years, 17 girls, 21 boys). A post hoc power analysis was conducted on $G^{*}$ Power 3.1 (https:/ / www.psychologie.hhu.de) to test the difference between two independent group means, using a two-tailed test, a medium effect size $(d=0.50)$, and an alpha of 0.05 . The result showed that the $t$-test between heavy-users and non-users groups could achieve a power of 0.32 . This limited statistical power was caused by the modest sample size in the present study $\left(\mathrm{N}_{\text {total }}=38\right)$, thus might have limited the significance of some of the statistical comparisons conducted.

\subsection{Measures}

\subsubsection{Home Learning Environment and Practice Survey (HLEP)}

This survey was used to collect information about young children's formal and informal learning activities at home. HLEP was developed from the Home Literacy Environment Index (HLEI) [19] and modified for early learning in the Chinese contexts [20]. HLEP had 29 questions about family background, household income, parental education level, occupation, home language, and learning environment, home learning activities, and bilingual parenting (TV watching time, parent-child talk time, storytelling time, parent-child shared reading time, the teaching of Chinese or English reading and writing, early bilingual literacies and so on). Some items were rated on a 5-point scale, while most asked for the real number of books, hours, frequencies, or ages, such as frequency of reading to the child per week, quantity, and variety of books in Chinese. In particular, four questions were asked about the child's tablet use at home. "Q15: Is your child allowed to use tablets (smartphone) at home? (yes; no)", "Q16: What does your child do with tablets? (1) watch cartoons or videos; (2) listen to music; (3) play game; (4) chat with friends or others; (5) others", "Q17: Your child's total screen time is __ minute/day", and "Q18: When does your child use tablets? (1) bedtime; (2) time assigned by the parent; (3) time chosen by the child; (4) when parents are busy". If the answer to Q15 is "no" and that to Q17 is "0 or Not/Applicable", the child will be regarded as 'non-user' of tablets. Accordingly, eight children were included in the 'non-user' group ( 2 girls, 6 boys). Among the 30 tablet users, 16 (12 girls, 4 boys) were classified into the 'heavy-user' group because: (1) their daily screen time was more than the mean level $(\mathrm{M}=17.98 \mathrm{~min}, \mathrm{SD}=14.29)$; (2) their use was neither controlled nor limited; and (3) they did multiple activities with tablets. In addition, the rest was classified into the 'low-user' group ( $n=14,3$ girls, 11 boys), thus was removed from the comparative analysis.

\subsubsection{The Dimensional Change Card Sort (DCCS) Tasks}

A set of white paper cards $(3.5 \mathrm{~cm} \times 7.0 \mathrm{~cm})$ were used as the stimuli. The stimuli had two dimensions: shape and color. The DCCS task included target cards and test cards, which were matched in one dimension but did not match the other dimension (e.g., a red boat, a blue rabbit). Further, the rule for matching was changed according to the experimenter's instruction. The present experiments included two target cards and 18 test cards, each of which was different in shape and color. One pair of target trays was used for the three consecutive test sessions, as shown in Figure 1. Each session consisted of a rest (20 s) phase and mix (25 s) phase, as shown in Figure 2. During the rest phase, children were asked to be still, doing nothing. During the mix phase, the children were asked to sort the cards according to the instructed rule (color or shape). In each phase, the children were given the rule before each trial. The rule order was fixed: shape, shape, color, shape, shape, 
color, shape, shape. The percentage of correct responses for each subject was recorded and analyzed. Each participant underwent a training session and three rounds of DCCS tasks. The training included six trials and allowed correction when children misunderstood the rules.

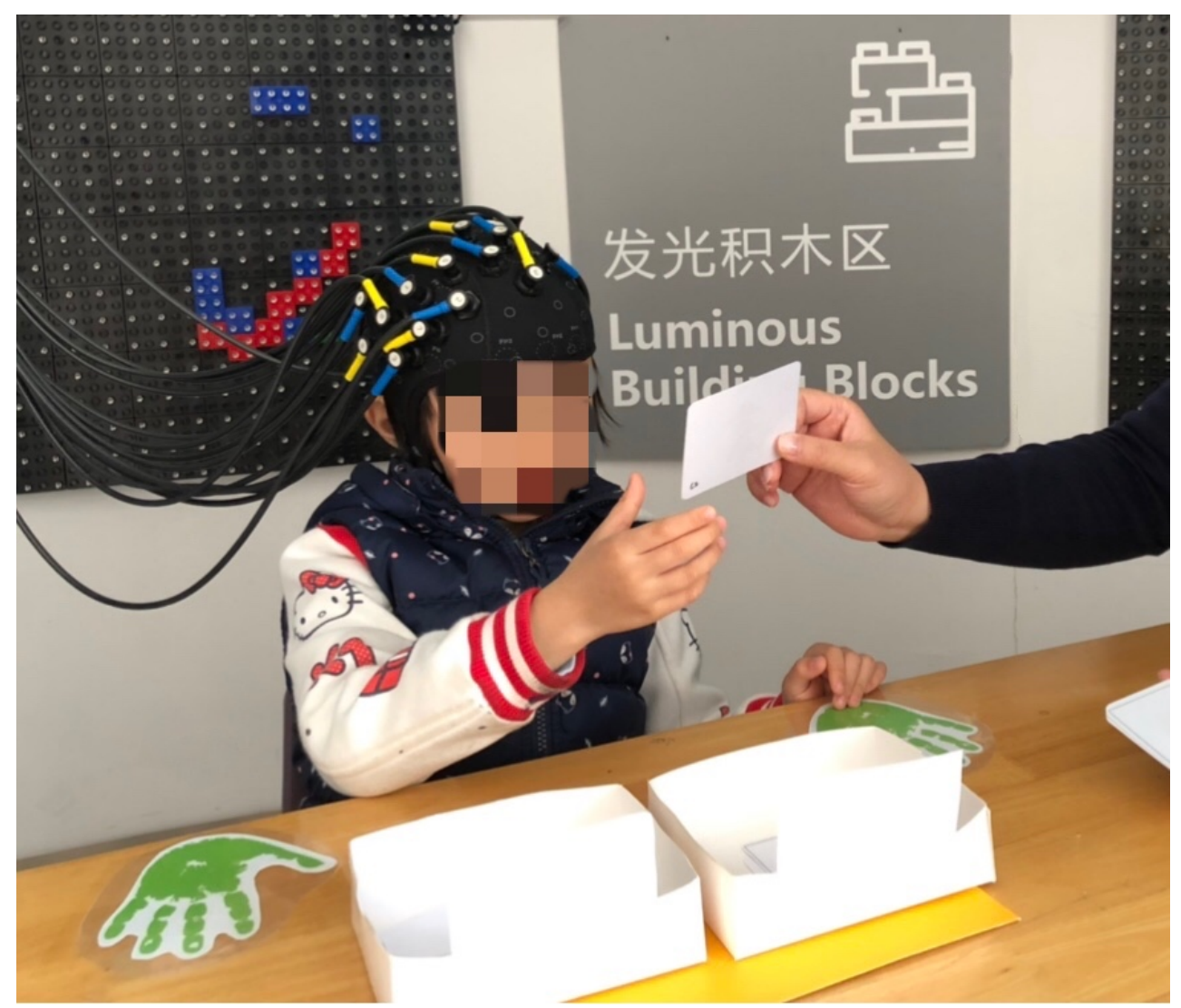

Figure 1. The Dimensional Change Card Sort (DCCS) tasks.
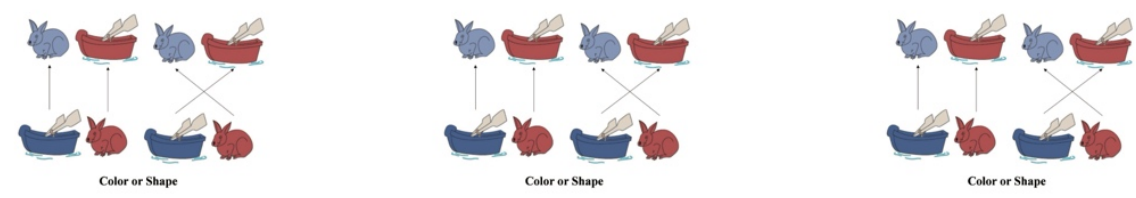

\begin{tabular}{|c|c|c|c|c|c|}
\hline Rest & MIX & Rest & MIX & Rest & MIX \\
\hline $20 \mathrm{~s}$ & $25 \mathrm{~s}$ & $20 \mathrm{~s}$ & $25 \mathrm{~s}$ & $20 \mathrm{~s}$ & $25 \mathrm{~s}$
\end{tabular}

Figure 2. The DCCS task paradigm.

\subsubsection{The fNIRS Examination}

In this study, a multiple-channel fNIRS system (Oxymon Mk III, Artinis, The Netherlands) was used to simultaneously measure the concentration changes of oxygenated hemoglobin $(\mathrm{HbO})$, deoxygenated hemoglobin $(\mathrm{HbR})$, and total hemoglobin $(\mathrm{HbT})$ in the participants. Two wavelengths in the near-infrared range (i.e., 760 and $850 \mathrm{~nm}$ ) were used to measure the changes in optical density and then converted into changes in the concentration of $\mathrm{HbO}$ and $\mathrm{HbR}$ using the modified Beer-Lambert law. The 17 channels were located following the international 10/20 system for EEG, with a $2.5 \mathrm{~cm}$ distance between each paired emitters and detectors. The region of interest (ROI) was located at Brodmann areas (BAs) 6/8/9/10/40/44 (Figure 3). Previous studies have shown that these areas were involved in EF in preschool children [10,11]. In particular, channels 1 and 9 were located in BA 6, channels 13, 15, 17 were located in BA 10, channel 10 was located 
in BA 8, channels 11, 12, 14, 16 were located in BA 9, channel 4 was located in BA 40, and channels 2, 3, 5, 6, 7, and 8 were located in the right IFC (BA 44).
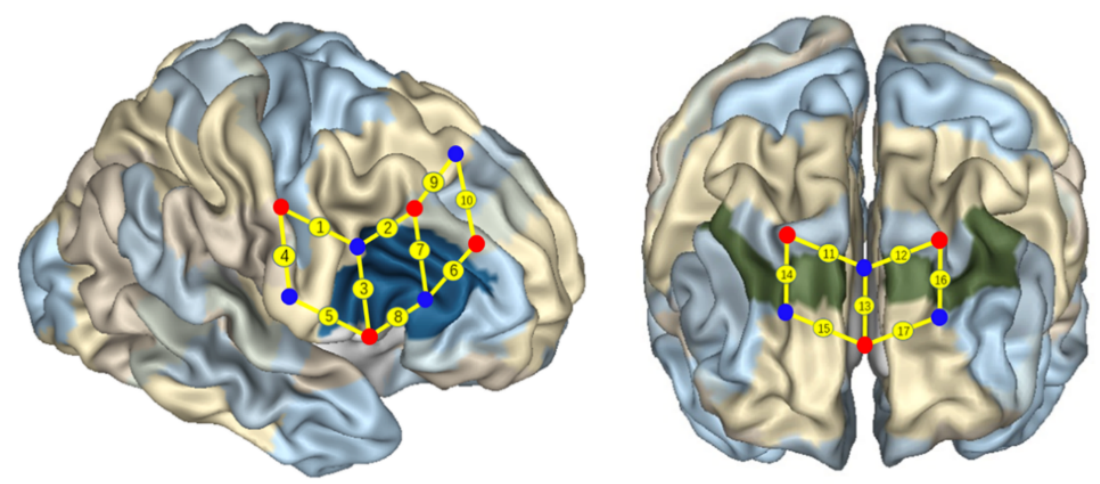

Figure 3. Localization of regions of interest.

\subsection{Procedure}

The study was conducted according to the guidelines of the Declaration of Helsinki, and was approved by the Ethics Committee of Shenzhen University (No. 2018005; January 2018).

\subsubsection{Data Collecting}

The child caps accompanied with the NIRS instrument have digitized the optode positions. Both S and XS size of NIRS caps were used in this study to fit the head size of Chinese preschoolers. An experienced NIRS technician conducted cap placement, hair manipulation and tossing, and optodes installation (based on the 10/20 system). This process usually took $10 \mathrm{~min}$, during which the participant was engaged in story-book reading with an experienced preschool teacher.

\subsubsection{Data Processing}

A subject-specific differential path-length factor (DPF) constant was calculated based on each subject's age, and the sampling rate was set at $50 \mathrm{~Hz}$ for data acquisition [21]. Each child's DPF value was calculated according to the formula (DPF $=4.99+0.0678 \mathrm{Age}^{0.814}$ ), which is more conducive to the data's accuracy. The trials that contained deformity or noisy data were treated as incorrect trials and were discarded in advance of the formal analysis. The raw optical intensity data series were converted into changes in optical density (OD). The discrete wavelet transform was applied to every channel data series to remove motion artifacts, with the tuning parameter $(\alpha)$ of wavelet filtering set at 0.1 . The bandpass filter (third-order Butterworth filter) with cut-off frequencies of $0.01-0.3 \mathrm{~Hz}$ was applied to reduce slow drifts and high-frequency noise. The OD data were then converted into concentration changes of $\mathrm{HbO}$ and $\mathrm{HbR}$.

\subsubsection{Data Analysis}

$\mathrm{HbO}$ and $\mathrm{HbR}$ concentration was converted into z-scores and calculated in the following analysis. Individual data were processed using MATLAB 2013b (Mathworks, MA, USA) and analyzed using the Homer2 NIRS processing package. The mean of z-scores $(\mathrm{HbO}$ and $\mathrm{HbR})$ was calculated for each DCCS task block separately for each participant. Then, the mean of z-scores ( $\mathrm{HbO}$ and $\mathrm{HbR}$ ) was calculated by averaging across the three task blocks for each participant. Finally, the mean of z-scores ( $\mathrm{HbO}$ and $\mathrm{HbR}$ ) across all channels were compared using $t$-tests between 'non-user' and 'heavy-user' groups using SPSS. The General Linear Model (GLM) analysis predicting z-scores ( $\mathrm{HbO}$ and $\mathrm{HbR}$ ) in channel 16 was conducted in $R\left(Y_{\Delta H b O}=a X_{\text {time }}+b+\varepsilon\right)$. 


\section{Results}

\subsection{Behavioral Results}

We compared the 'non-user' and 'heavy-user' groups' behavioral performance in the DCCS task (See Table 1). First, $t$-tests indicated that there were no significant differences in age between the 'non-user' $\left(M_{\text {Non-user }}=5.03, S D=0.41\right)$ and 'heavy-user' $\left(M_{\text {Heavy-user }}=4.80\right.$, $S D=0.68)$ groups, $t=0.85, p>0.001$. Second, all the 'non-user' children passed all the testing items, $M_{\text {correct rate }}=1$. In contrast, not all the 16 'heavy-user' children passed all the testing items, $M_{\text {correct rate }}=0.922, S D=0.14$. The $t$-test results indicated that the 'non-user' group significantly outperformed the 'heavy-user' group, $t=2.256, p<0.05$.

Table 1. Comparison of behavioral performance (correct rate) in the DCCS task.

\begin{tabular}{ccccc}
\hline & Non-Users Mean (SD) & Heavy Users Mean $(S D)$ & $\boldsymbol{t}$ & $\boldsymbol{p}$ \\
\hline Age & $5.03(0.41)$ & $4.80(0.68)$ & 0.850 & 0.404 \\
DCCS Score & $1(0)$ & $0.922(0.14)$ & 2.256 & 0.039 * \\
\hline Note: ${ }^{*} p<0.05$. & & &
\end{tabular}

\section{2. fNIRS Results}

First, a set of independent-samples $t$-tests were conducted to determine whether there were significant differences in $\mathrm{HbO}$ increases in the 17 channels between the 'non-user' and 'heavy-user' groups. As multiple channels were involved in this type of $t$-tests, all the results were corrected for multiple comparisons using the false discovery rate (FDR), and the adjusted significance level of $p$-value was set at 0.05 . As shown in Table 2 and Figure 4, significant differences were found only in BA 9 (ch 16) $(t=2.285, p<0.05)$ between the 'non-user' $\left(M_{H b O}=1.17, S D=2.02\right)$ and the 'heavy-user' $\left(M_{H b O}=-0.62, S D=1.70\right)$ groups. This result indicated that the 'non-user' group had significantly more activation in BA 9 than the 'heavy-user' group.

Table 2. Comparison of $\mathrm{HbO}$ increase between 'non-user' $\left(\mathrm{N}_{1}=8\right)$ and 'heavy-user' $\left(\mathrm{N}_{2}=16\right)$ groups.

\begin{tabular}{|c|c|c|c|c|c|}
\hline & Group & $M$ & $S D$ & $t$ & $p$ \\
\hline \multirow{2}{*}{ Channel 1} & Non-user & -0.692 & 2.045 & -0.511 & 0.615 \\
\hline & Heavy-user & -0.248 & 1.989 & & \\
\hline \multirow{2}{*}{ Channel 2} & Non-user & -1.414 & 1.630 & -1.468 & 0.156 \\
\hline & Heavy-user & -0.105 & 2.230 & & \\
\hline \multirow{2}{*}{ Channel 3} & Non-user & -1.024 & 1.454 & 0.011 & 0.991 \\
\hline & Heavy-user & -1.034 & 2.297 & & \\
\hline \multirow{2}{*}{ Channel 4} & Non-user & -0.269 & 1.550 & -0.178 & 0.86 \\
\hline & Heavy-user & -0.146 & 1.628 & & \\
\hline \multirow{2}{*}{ Channel 5} & Non-user & -0.439 & 2.180 & -0.318 & 0.753 \\
\hline & Heavy-user & -0.176 & 1.767 & & \\
\hline \multirow{2}{*}{ Channel 6} & Non-user & -0.460 & 0.698 & -1.162 & 0.258 \\
\hline & Heavy-user & -0.045 & 0.877 & & \\
\hline \multirow{2}{*}{ Channel 7} & Non-user & -0.660 & 1.699 & -0.803 & 0.431 \\
\hline & Heavy-user & 0.111 & 2.423 & & \\
\hline \multirow{2}{*}{ Channel 8} & Non-user & -1.198 & 2.068 & -0.633 & 0.533 \\
\hline & Heavy-user & -0.603 & 2.222 & & \\
\hline \multirow{2}{*}{ Channel 9} & Non-user & -0.356 & 0.603 & -1.534 & 0.139 \\
\hline & Heavy-user & -0.015 & 0.466 & & \\
\hline \multirow{2}{*}{ Channel 10} & Non-user & 0.360 & 1.667 & -0.172 & 0.865 \\
\hline & Heavy-user & 0.465 & 1.256 & & \\
\hline \multirow[b]{2}{*}{ Channel 11} & Non-user & 0.052 & 1.322 & -1.287 & 0.211 \\
\hline & Heavy-user & 0.761 & 1.247 & & \\
\hline \multirow[b]{2}{*}{ Channel 12} & Non-user & 0.406 & 2.823 & 0.502 & 0.621 \\
\hline & Heavy-user & -0.044 & 1.606 & & \\
\hline \multirow{2}{*}{ Channel 13} & Non-user & 0.790 & 3.030 & 0.457 & 0.652 \\
\hline & Heavy-user & 0.352 & 1.702 & & \\
\hline
\end{tabular}


Table 2. Cont.

\begin{tabular}{cccccc}
\hline \multirow{2}{*}{ Channel 14 } & Group & $\boldsymbol{M}$ & $\boldsymbol{S D}$ & $\boldsymbol{t}$ & $\boldsymbol{t}$ \\
& Non-user & -0.804 & 0.984 & -0.772 & 0.448 \\
& Heavy-user & -0.142 & 2.304 & & \\
Channel 15 & Non-user & 0.444 & 2.123 & 0.48 & 0.636 \\
& Heavy-user & 0.037 & 1.882 & & \multirow{2}{*}{$0.032 *$} \\
Channel 16 & Non-user & 1.166 & 2.019 & 2.285 & \multirow{2}{*}{ * } \\
& Heavy-user & -0.623 & 1.699 & & 0.477 \\
& Non-user & 0.391 & 1.057 & 0.724 & \\
\hline
\end{tabular}

DCCS (HbO)
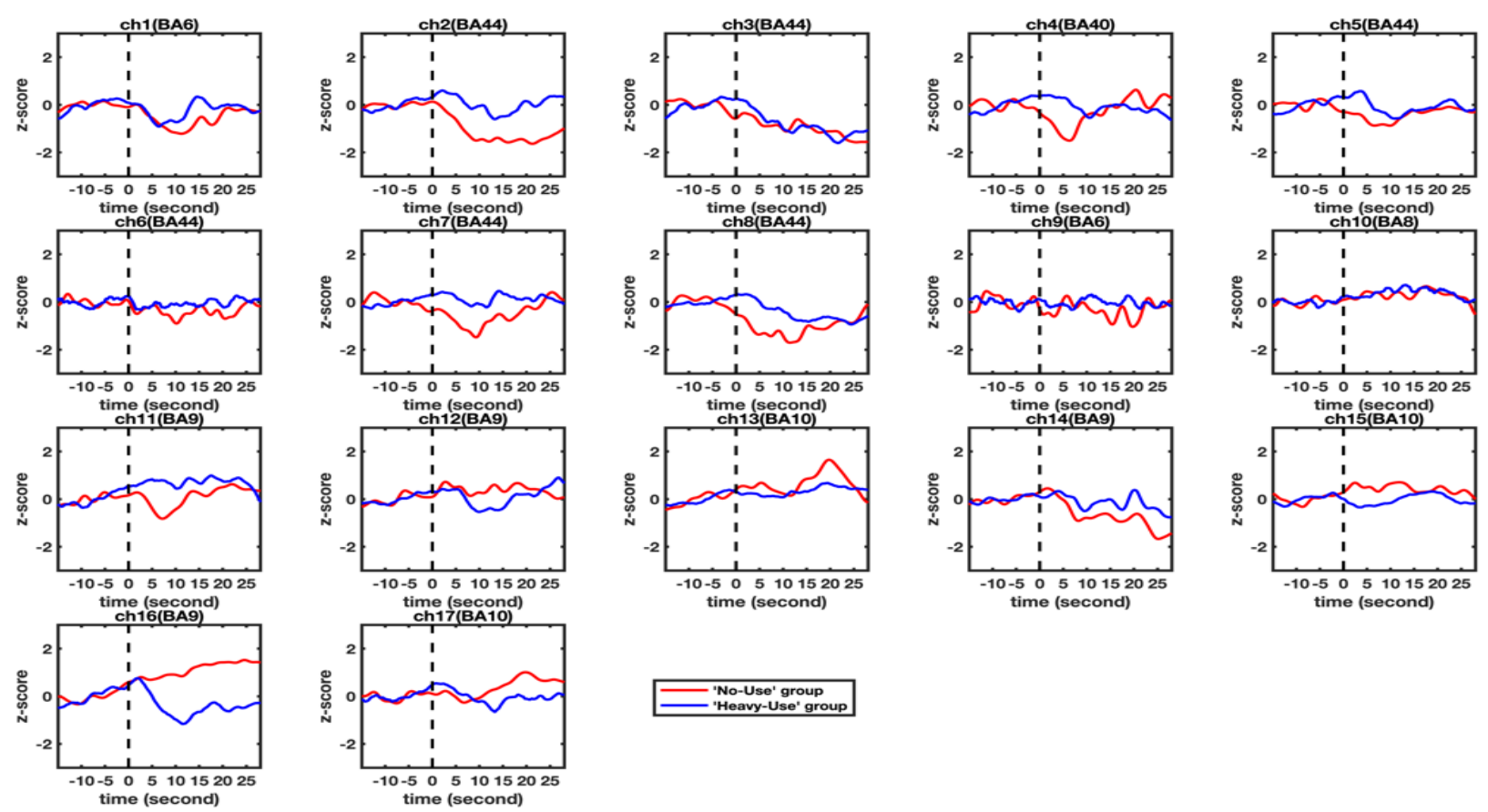

Figure 4. Observed changes in the $\mathrm{HbO}$ concentration in the 17 channels during the DCCS tasks. The HbO data for the 'non-user' and 'heavy-user' group are shown in red and blue line, respectively.

Second, a set of independent-sample $t$-tests were conducted to determine whether there were significant differences in HbR increases in the 17 channels between the 'non-user' and 'heavy-user' groups. As shown in Table 3 and Figure 5, no significant differences were found in any channel, ts $<1.441, p s>0.164$, after corrected with FDR.

Table 3. Comparison of HbR increase between 'non-user' $\left(\mathrm{N}_{1}=8\right)$ and 'heavy-user' $\left(\mathrm{N}_{2}=16\right)$ groups.

\begin{tabular}{cccccc}
\hline \multirow{2}{*}{ Channel 1 } & Group & $\boldsymbol{M}$ & $S D$ & $t$ & $p$ \\
& Non-user & -0.305 & 1.768 & 0.604 & 0.552 \\
Channel 2 & Heavy-user & -0.895 & 2.452 & & \\
& Non-user & 0.583 & 2.760 & 0.307 & 0.762 \\
& Heavy-user & 0.282 & 1.990 & & \\
Channel 3 & Non-user & 0.304 & 1.521 & 0.647 & 0.524 \\
& Heavy-user & -0.139 & 1.609 & & \multirow{2}{*}{0.967} \\
& Non-user & -0.083 & 2.041 & -0.041 & \\
Channel 4 & Heavy-user & -0.045 & 2.186 & & \multirow{2}{*}{0.989} \\
& Non-user & 0.486 & 2.210 & 0.014 & \\
\hline
\end{tabular}


Table 3. Cont.

\begin{tabular}{|c|c|c|c|c|c|}
\hline & Group & $M$ & $S D$ & $t$ & $p$ \\
\hline \multirow{2}{*}{ Channel 6} & Non-user & 0.277 & 0.734 & 1.339 & 0.194 \\
\hline & Heavy-user & -0.055 & 0.479 & & \\
\hline \multirow{2}{*}{ Channel 7} & Non-user & -0.289 & 1.472 & -0.566 & 0.577 \\
\hline & Heavy-user & 0.178 & 2.076 & & \\
\hline \multirow{2}{*}{ Channel 8} & Non-user & -0.482 & 2.949 & 0.162 & 0.872 \\
\hline & Heavy-user & -0.702 & 3.215 & & \\
\hline \multirow[b]{2}{*}{ Channel 9} & Non-user & -0.212 & 0.631 & -0.637 & 0.530 \\
\hline & Heavy-user & -0.062 & 0.497 & & \\
\hline \multirow{2}{*}{ Channel 10} & Non-user & 0.470 & 1.988 & -0.253 & 0.802 \\
\hline & Heavy-user & 0.634 & 1.186 & & \\
\hline \multirow{2}{*}{ Channel 11} & Non-user & 1.233 & 1.060 & 1.441 & 0.164 \\
\hline & Heavy-user & 0.178 & 1.914 & & \\
\hline \multirow{2}{*}{ Channel 12} & Non-user & 0.203 & 1.020 & 0.329 & 0.745 \\
\hline & Heavy-user & 0.027 & 1.327 & & \\
\hline \multirow{2}{*}{ Channel 13} & Non-user & 0.683 & 2.835 & -0.042 & 0.966 \\
\hline & Heavy-user & 0.724 & 1.848 & & \\
\hline \multirow{2}{*}{ Channel 14} & Non-user & 1.378 & 1.535 & 1.107 & 0.280 \\
\hline & Heavy-user & 0.536 & 1.851 & & \\
\hline \multirow{2}{*}{ Channel 15} & Non-user & 1.276 & 1.816 & 0.519 & 0.609 \\
\hline & Heavy-user & 0.699 & 2.846 & & \\
\hline \multirow[b]{2}{*}{ Channel 16} & Non-user & -0.167 & 2.602 & -0.072 & 0.943 \\
\hline & Heavy-user & -0.109 & 1.395 & & \\
\hline \multirow{2}{*}{ Channel 17} & Non-user & 0.391 & 1.784 & 0.127 & 0.900 \\
\hline & Heavy-user & 0.298 & 1.651 & & \\
\hline
\end{tabular}

$\operatorname{DCCS}(\mathrm{HbR})$
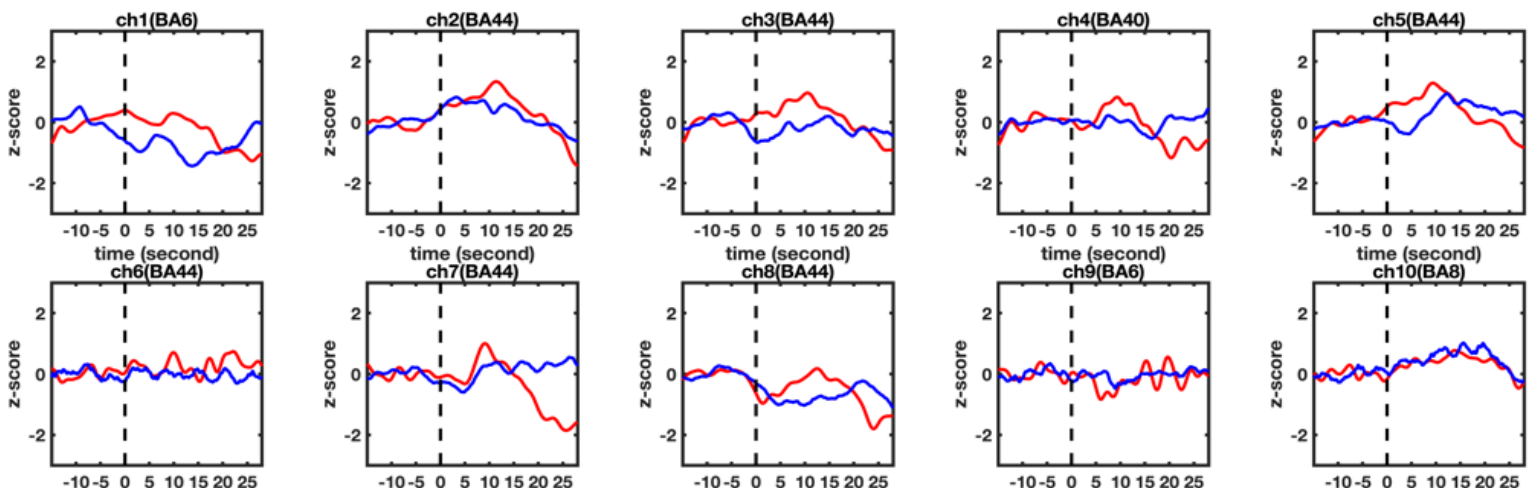

time (second)
ch7(BA44)

time (second)
ch8(BA44)
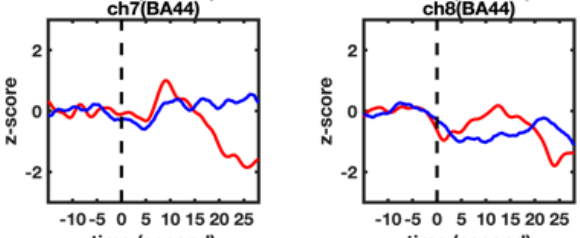

time (second

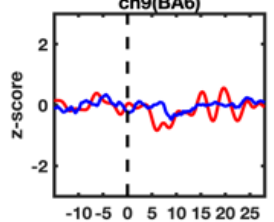

time (second)

time (second)
ch12(BA9)
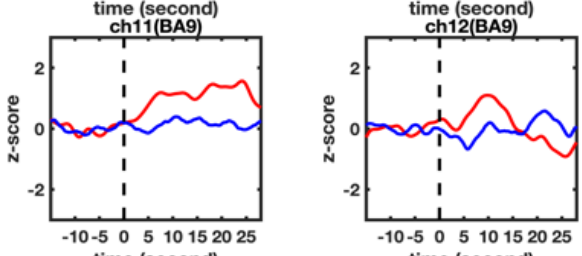

time
ch13(BA10)

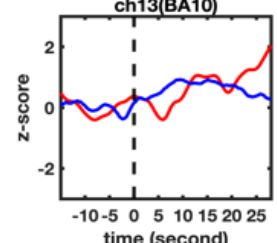

time (second)
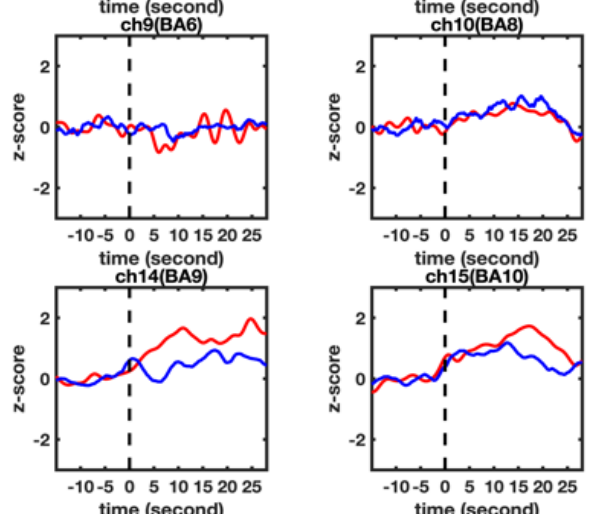

time (second)
ch16(BA9) time (second)
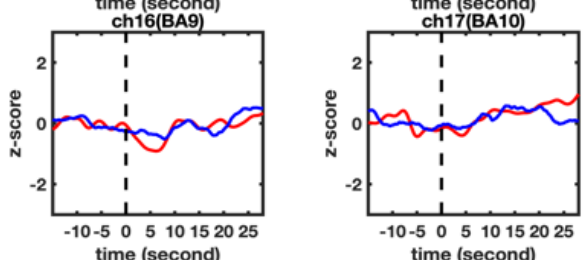

time (second)

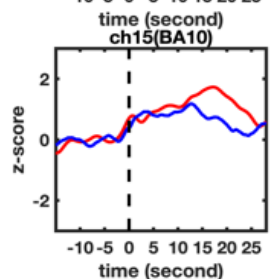

Figure 5. Observed changes in the HbR concentration in the 17 channels during the DCCS tasks. The HbR data for the 'non-user' and 'heavy-user' group are shown in red and blue line, respectively. 
Third, a set of GLM analyses were conducted to model the changes in $\mathrm{HbO}$ in channel 16 based on experiment time for the 'non-user' and 'heavy-user' groups, respectively. As shown in Table 4 and Figure 6, during the DCCS task, significant $\mathrm{HbO}$ increase was observed in BA 9 (channel 16) for the 'non-user' group, $\beta=0.94, \Delta R^{2}=0.89, F=803.45$ (for the model), $t=28.35$ (for $\beta$ ), $p<0.001$. In contrast, significant decreases were found in BA 9 (channel 16) for the 'high-use' group, $\beta=-0.33, \Delta R^{2}=0.10, F=12.17$ (for the model), $t=-3.49$ (for $\beta$ ), $p<0.01$. However, after the 12 th second, there was an increase in $\mathrm{HbO}$ in the 'heavy-user' group. These results indicated that BA 9 was significantly activated in the 'non-user' group during the DCCS task.

Table 4. Predicting $\mathrm{HbO}$ increase for the 'non-user' and 'heavy-user' groups in BA 9.

\begin{tabular}{ccccc}
\hline Group & $\boldsymbol{\beta}$ & $\boldsymbol{\Delta} \boldsymbol{R}^{\mathbf{2}}$ & $\boldsymbol{F}$ & $\boldsymbol{t}$ \\
\hline Non-user & 0.944 & 0.890 & $803.452^{* * *}$ & $28.345^{* * *}$ \\
'Heavy-user' & -0.332 & 0.101 & $12.171^{* *}$ & $-3.489^{* *}$ \\
\hline Note: ${ }^{* *} p<0.01$; $^{* * *} p<0.001$. & & &
\end{tabular}

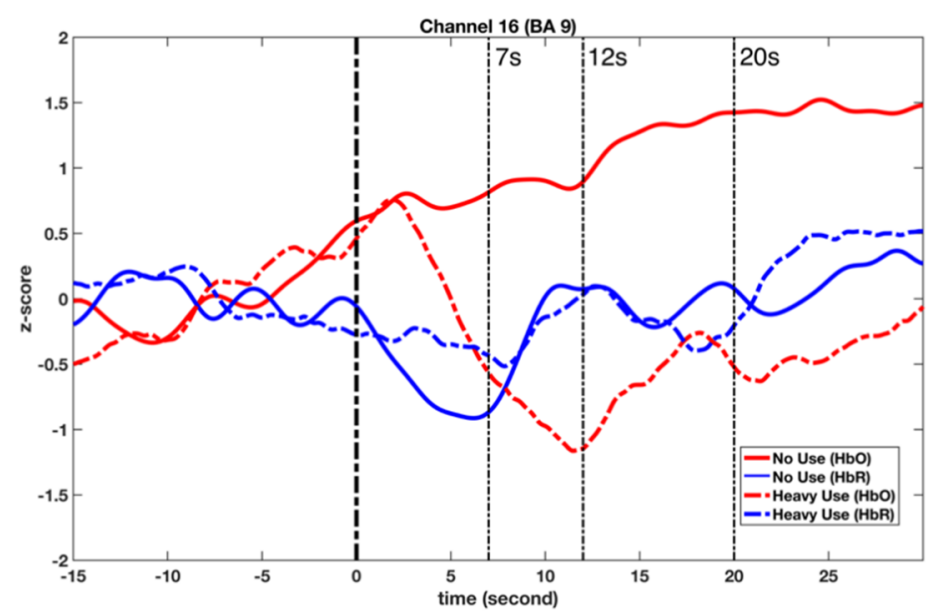

Figure 6. Observed changes in the $\mathrm{HbO}$ and $\mathrm{HbR}$ concentration in BA 9 (ch 16) during the DCCS tasks.

Last, a set of GLM analyses was conducted to model the changes in $\mathrm{HbR}$ in Channel 16 based on experiment time for the 'non-user' and 'heavy-user' groups, respectively. As shown in Table 5 and Figure 6, during the DCCS task, significant HbR increase was observed in BA 9 (channel 16) for both 'non-user' $\left[\beta=0.76, \Delta R^{2}=0.58, F=134.99\right.$ (for the model), $t=-3.49$ (for $\beta$ ), $p<0.01]$ and 'heavy-user' groups $\left[\beta=0.81, \Delta R^{2}=0.65, F=182.73\right.$ (for the model), $t=13.52$ (for $\beta$ ), $p<0.01$ ]. In particular, a significant decrease in HbR could be observed in the 'non-user' group before the 7th second. A significant decrease was observed in the 'heavy-user' group during 12th to 20th second.

Table 5. Predicting HbR increase for the 'non-user' and 'heavy-user' groups in BA 9.

\begin{tabular}{ccccc}
\hline Group & $\boldsymbol{\beta}$ & $\boldsymbol{\Delta} \boldsymbol{R}^{2}$ & $\boldsymbol{F}$ & $\boldsymbol{t}$ \\
\hline Non-user & 0.761 & 0.575 & $134.987^{* * *}$ & $11.618^{* * *}$ \\
Heavy-user & 0.807 & 0.647 & $182.730^{* * *}$ & $13.518^{* * *}$ \\
\hline Note: $* * *$ \\
\hline
\end{tabular}

\section{Discussion}

\section{1. 'Non-User' Outperformed 'Heavy-User' Group in the DCCS}

This study found that the young children who never used tablets had a 100\% correct rate in the DCCS task, significantly outperforming those 'heavy-users'. This finding is consistent with Horowitz-Kraus and Hutton [22], who found that increased screen time 
was associated with poorer executive functioning in very young children. In a systematic review, Small et al. also found that frequent tablet use might negatively affect brain function and behavior [3]. All these findings have jointly confirmed that tablet use has adversely impacted young children's executive function. For the first time, this study provides fNIRS evidence to demonstrate the negative impact of tablet use, as discussed in the next section.

\subsection{Two Activation Patterns in BA 9}

This study found two distinctive activation patterns in BA 9 when processing the DCCS tasks. First, the 'non-user' pattern features a significant increase in $\mathrm{HbO}$ and a significant decrease in $\mathrm{HbR}$ before the 7 th second during the task. This indicates a typical activation of BA 9, as an increase in $\mathrm{HbO}$ and a decrease in $\mathrm{HbR}$ are required to make a functional activation. Although the link to blood flow is only indirect and should be treated with care, this paired increase-decrease change in $\mathrm{HbO}$ and $\mathrm{HbR}$ demonstrates a complete hemodynamic picture. In fNIRS research, $\mathrm{HbO}$ is mainly linked to the tissue's oxygen inflow, while $\mathrm{HbR}$ is linked to the amount of oxygen absorbed by the tissue [23]. In homeostasis, both the inflow of $\mathrm{HbO}$ and the formation of $\mathrm{HbR}$ should be constant, as the amount of oxygen being consumed by the tissue is equal to the amount of oxygen being carried towards the tissue. During the activation of BA 9, oxygen is consumed within the tissue, and hemodynamically, the tissue responds by increasing blood flow toward that area [24]. Therefore, this 'non-user' activation pattern could be regarded as normal and healthy.

Second, the 'heavy-user' pattern features a significant decrease in $\mathrm{HbO}$ and an increase in $\mathrm{HbR}$ in BA 9. However, a remarkable increase in $\mathrm{HbR}$ (since 8th second) and $\mathrm{HbO}$ (since 12th second) was also found. According to the hemodynamic rule, the concentration of $\mathrm{HbO}$ is expected to rise after the activation of the prefrontal cortex due to the higher blood flow. In contrast, $\mathrm{HbR}$ is washed out, and its concentration should decrease [23]. Therefore, the 'heavy-user' pattern has two unexpected features observed in the DCCS task. The first unusual feature is the significant decrease in $\mathrm{HbO}$ before the 12th second, reflecting BA 9 might not be activated during this period. The second unusual feature is the synchronous increase in $\mathrm{HbO}$ and $\mathrm{HbR}$ after the 12th second, which is inconsistent with the hemodynamic rule [24]. During activation of BA 9, there should be an increase in $\mathrm{HbO}$ but a decrease in $\mathrm{HbR}$ [24]. However, this unexpected synchronous increase in $\mathrm{HbO}$ and $\mathrm{HbR}$ was also found by Nguyen et al. during epileptic seizures [25]. They found that an initial decrease in $\mathrm{HbR}$ was followed by its increase, indicating an increase in oxygen metabolism is not sufficiently compensated during the epileptic seizures. Therefore, we tend to suggest that this 'heavy-user' activation pattern might be abnormal and very likely unhealthy, demonstrating the negative impact of tablet use on young children's executive function. However, future studies are needed to further explore this synchronous increase phenomenon and its hemodynamic mechanisms.

\section{Conclusions, Limitations, and Implications}

This study adopted fNIRS technology to explore the impact of heavy use of tablets on preschoolers' executive function. It found that the 'non-user' group outperformed the 'heavy-user' with a significantly higher correct rate in the DCCS task. The 'non-user' brain activation pattern in BA 9 is normal and healthy, whereas the 'heavy-user' pattern is not normal and deserves further studies.

However, this study did have four major limitations. First, fNIRS data acquisition could have been disturbed by movement during the DCCS task. Fortunately, the prefrontal cortex is associated with little movement and consists mainly of executive function. In the future, EEG-fNIRS signals should be simultaneously collected to further understand the activation pattern in BA 9 for those heavy users. The second limitation is the small sample size. Due to the unexpected lockdown caused by the COVID-19 outbreak in China, we had to stop the experiment after testing the 38 samples. This problem might have limited the significance of some of the statistical comparisons in this study. Third, although the total 
sample was balanced in gender, the different groups had an unbalanced allocation of boys and girls. Future studies should consider this variable if aiming to examine the gender difference in brain activation. Fourth, although there is evidence of a brain activation pattern similar to that of seizures, there is no indication of any permanent damage in BA 9 for those heavy users. All these limitations jointly imply that further studies are necessary to study the consequences of heavy use of tablets, using both longitudinal and EEG-NIRS data.

Author Contributions: Conceptualization, H.L. and D.W.; methodology, C.C., J.Y., D.W.; formal analysis, J.Y., H.L.; investigation, D.W., J.Y., J.L., S.X.; resources, C.C., S.X.; data curation, J.Y.; writing—original draft preparation, J.Y., D.W.; writing—review and editing, H.L.; visualization, J.Y.; supervision, H.L., C.C.; project administration, D.W.; funding acquisition, C.C. All authors have read and agreed to the published version of the manuscript.

Funding: This work was supported by the National Natural Science Foundation of China (61971289), Shenzhen Fundamental Research Project (JCYJ20170412111316339), and Shenzhen-Hong Kong Institute of Brain Science-Shenzhen Fundamental Research Institutions. The APC was funded by Macquarie University, Australia.

Institutional Review Board Statement: The study was conducted according to the guidelines of the Declaration of Helsinki, and approved by the Ethics Committee of Shenzhen University (No. 2018005; January 2018).

Informed Consent Statement: Informed consent was obtained from all the participating parents involved in the study.

Data Availability Statement: All the data for this study will be available upon request.

Acknowledgments: The authors are incredibly grateful to Weili Wang and Xiuhong Wang, and all the teachers, parents and children of Shenzhen No. 8 Kindergarten, China.

Conflicts of Interest: The authors declare no conflict of interest.

\section{References}

1. Savina, E.; Mills, J.L.; Atwood, K.; Cha, J. Digital Media and Youth: A Primer for School Psychologists. Contemp. Sch. Psychol. 2017, 21, 80-91. [CrossRef]

2. Rocha, B.; Nunes, C. Benefits and damages of the use of touchscreen devices for the development and behavior of children under 5 years old-A systematic review. Psicologia Reflexão e Crítica 2020, 33, 1-10. [CrossRef] [PubMed]

3. Small, G.W.; Lee, J.; Kaufman, A.; Jalil, J.; Siddarth, P.; Gaddipati, H.; Moody, T.D.; Bookheimer, S.Y. Brain health consequences of digital technology use. Dialog Clin. Neurosci. 2020, 22, 179-187. [CrossRef]

4. Beatty, C.; Egan, S.M. Screen time in early childhood: A review of prevalence, evidence and guidelines. An Leanhb Óg 2020, 13, $17-31$.

5. McEwen, R.; Dubé, A.K. Intuitive or idiomatic: An interdisciplinary study of child-tablet computer interaction. J. Assoc. Inf. Sci. Technol. 2015, 67, 1169-1181. [CrossRef]

6. Neumann, M.M.; Neumann, D.L. Touch Screen Tablets and Emergent Literacy. J. Fam. Econ. Issues 2013, 42, 231-239. [CrossRef]

7. Dong, C.; Cao, S.; Li, H. Young children's online learning during COVID-19 pandemic: Chinese parents' beliefs and attitudes. Child. Youth Serv. Rev. 2020, 118, 105440. [CrossRef]

8. Sivrikova, N.V.; Ptashko, T.G.; Perebeynos, A.E.; Chernikova, E.G.; Gilyazeva, N.V.; Vasilyeva, V.S. Parental reports on digital devices use in infancy and early childhood. Educ. Inf. Technol. 2020, 25, 3957-3973. [CrossRef]

9. Lawrence, S.M. Preschool Children and iPads: Observations of Social Interactions During Digital Play. Early Educ. Dev. 2017, 29, 207-228. [CrossRef]

10. Xie, S.; Wu, D.; Yang, J.; Luo, J.; Chang, C.; Li, H. An fNIRS examination of executive function in bilingual young children. Int. J. Biling. 2020. [CrossRef]

11. Li, H.; Wu, D.; Yang, J.; Xie, S.; Luo, J.; Chang, C. A Functional Near-Infrared Spectroscopy Examination of the Neural Correlates of Cognitive Shifting in Dimensional Change Card Sort Task. Front. Hum. Neurosci. 2021, 14, 561223. [CrossRef] [PubMed]

12. Miyake, A.; Friedman, N.P.; Emerson, M.J.; Witzki, A.H.; Howerter, A.; Wager, T.D. The Unity and Diversity of Executive Functions and Their Contributions to Complex “Frontal Lobe" Tasks: A Latent Variable Analysis. Cogn. Psychol. 2000, 41, 49-100. [CrossRef] [PubMed]

13. Buss, A.T.; Spencer, J.P. Changes in frontal and posterior cortical activity underlie the early emergence of executive function. Dev. Sci. 2017, 21, e12602. [CrossRef] [PubMed] 
14. Moriguchi, Y.; Hiraki, K. Neural origin of cognitive shifting in young children. Proc. Natl. Acad. Sci. USA 2009, 106, 6017-6021. [CrossRef] [PubMed]

15. Moriguchi, Y. Neural mechanisms of executive function development during early childhood. In Executive Function; Wiebe, S.A., Karbach, J., Eds.; Routledge: New York, NY, USA, 2017; pp. 89-104.

16. Blair, C. Developmental Science and Executive Function. Curr. Dir. Psychol. Sci. 2016, 25, 3-7. [CrossRef]

17. NAEYC and Fred Rogers Center for Early Learning. In Technology and Interactive Media as Tools in Early Childhood Programs Serving Children from Birth through Age 8; Position Statement; NAEYC: Washington, DC, USA, 2012.

18. Rideout, V. The Common Sense Census: Media Use by Kids Age Zero to Eight; Common Sense Media: San Francisco, CA, USA, 2017.

19. Li, H.; Rao, N. Parental influences on Chinese literacy development: A comparison of preschoolers in Beijing, Hong Kong, and Singapore. Int. J. Behav. Dev. 2000, 24, 82-90. [CrossRef]

20. LI, H. Teaching Chinese Literacy in the Early Years: A Comparison of L1 and L2 Preschool Classrooms in Shenzhen and Singapore. Asia Pac. J. Res. Early Child. Educ. 2013, 7,3.

21. Duncan, A.; Meek, J.H.; Clemence, M.; Elwell, C.E.; Fallon, P.; Tyszczuk, L.; Cope, M.; Delpy, D.T. Measurement of Cranial Optical Path Length as a Function of Age Using Phase Resolved Near Infrared Spectroscopy. Pediatr. Res. 1996, 39, 889-894. [CrossRef]

22. Horowitz-Kraus, T.; Hutton, J.S. Brain connectivity in children is increased by the time they spend reading books and decreased by the length of exposure to screen-based media. Acta Paediatr. 2018, 107, 685-693. [CrossRef] [PubMed]

23. Lachert, P.; Janusek, D.; Pulawski, P.; Liebert, A.; Milej, D.; Blinowska, K.J. Coupling of Oxy- and Deoxyhemoglobin concentrations with EEG rhythms during motor task. Sci. Rep. 2017, 7, 1-9. [CrossRef]

24. Scholkmann, F.; Metz, A.J.; Wolf, M. Measuring tissue hemodynamics and oxygenation by continuous-wave functional nearinfrared spectroscopy-how robust are the different calculation methods against movement artifacts? Physiol. Meas. 2014, 35, 717-734. [CrossRef] [PubMed]

25. Nguyen, D.K.; Tremblay, J.; Pouliot, P.; Vannasing, P.; Florea, O.; Carmant, L.; Lepore, F.; Sawan, M.; Lesage, F.; Lassonde, M. Non-invasive continuous EEG-fNIRS recording of temporal lobe seizures. Epilepsy Res. 2012, 99, 112-126. [CrossRef] [PubMed]

\section{Short Biography of Authors}

Hui Li is a professor in Early Childhood at Macquarie University, Australia. He received his PhD in Education from the University of Hong Kong. His research interests include (but not limited to) developmental cognitive neuroscience, developmental psycholinguistics, early literacy, curriculum and pedagogy, policy, school leadership, and teacher education. His research methods include mixed-methods, longitudinal study, corpus, and fNIRS. He is the associate editor of Early Education and Development and Frontiers in Psychology, and the executive editor of Human Behavior and Brain.

Dandan Wu is a PhD candidate at Macquarie University, Australia. She received her M.Ed. in Early Childhood Education from the University of Hong Kong in 2014. Her PhD research focuses on the development of spatial language and concepts in preschoolers. Her research interests include psycholinguistic and neuroimaging approaches to early cognitive development and education.

Jinfeng Yang is a neuroimaging technician working at Prof C.Q. Chang's laboratory at Shenzhen University. He received his Master of Medical Engineering from Shenzhen University. He is now a neuroimaging technician at Henan Provincial People's Hospital, China.

Jiutong Luo is a postdoctoral research fellow at the Advanced Innovation Center for Future Education, Faculty of Education, Beijing Normal University, Beijing, China. He received his PhD in Education from the University of Hong Kong. His research interests include educational technology, children and youth studies, and developmental cognitive neuroscience.

Sha Xie is an assistant professor at the Normal College of Shenzhen University, China. She received her PhD from the University of Hong Kong. Her research interests lie in children's cognitive and social development as well as family studies. She is an editorial board member of Early Education and Development, and Frontiers in Psychology.

Chunqi Chang is a professor of Biomedical Engineering at Shenzhen University, China. He was awarded PhD degree by the University of Hong Kong. His research is in the broad areas of signal processing, biomedical engineering, computational systems biology, and brain and cognitive sciences, and his main research interests include neuroimaging, neuroinformatics, neuroengineering, and machine learning. He has published over 100 research papers on international journals and conference proceedings. 